\title{
Fetal intrapericardial teratomas
}

\author{
Shi-Min Yuan ${ }^{1}$, Hong Lin $^{2}$ \\ Departments of ${ }^{1}$ Cardiothoracic Surgery and ${ }^{2}$ Cardiology, The First Hospital of Putian, Teaching hospital, Fujian Medical \\ University, Putian, Fujian Province, China. E-mail: linhong0218@126.com \\ Received: 7th August 2018, Accepted: 9th October 2018
}

SUMMARY: Yuan SM, Lin H. Fetal intrapericardial teratomas. Turk J Pediatr 2019; 61: 153-158.

Fetal intrapericardial teratomas are rare and benign. However, they can be life-threatening owing to the complicated massive pericardial effusions, tamponade, or cardiorespiratory distress. The purpose of this review is to give an overview on clinical features, management and prognoses of fetal intrapericardial teratomas. The materials of this study were based on a comprehensive literature retrieval of fetal intrapericardial teratomas published in the past two decades. It was noteworthy that fetal pericardial/pleural effusions or ascites were detected since 19-week gestation, and tumors could be found since 21-week gestation. A growing trend of tumors was observed in more than half of the cases. Prenatal centesis and postnatal tumor resection were required in most of the cases. Fetoneonatal deaths (including fetal demise, termination of pregnancy and neonatal death) occurred in one-third of the cases. The neonatal survival rate was $59.4 \%$. Symptomatic fetuses usually required perinatal maneuvers, such as pericardiocentesis, or thoraco-/ pericardio-amniotic shunt in order to improve fetal hemodynamic status and prolong the pregnancy for lung maturity. Open fetal surgery and ex utero intrapartum treatment (EXIT) procedure can be considered, however, impact of EXIT procedure on later delivery remains uncertain. Postnatal operation is a curative and symptom-relieving method for those cases with prenatally diagnosed intrapericardial teratomas. As a result, the fetoneonatal outcomes are somewhat promising.

Key words: Pericardial teratoma, fetal surgery, fetus, hydrops.

Intrapericardial teratomas are rare primary cardiac tumors, accounting for $10 \%$ of mediastinal tumors of pediatric patients. ${ }^{1}$ Pathologically, intrapericardial teratomas contain endodermic, mesodermic and neuroectodermic germinal layers. ${ }^{2}$ Fetal intrapericardial teratomas are usually benign and asymptomatic, but sometimes complicated by cardiac compression, hydrops fetalis. ${ }^{3,4}$ The teratomas can sometimes be fatal due to the associated massive pericardial effusions, cardiac compression, ${ }^{2}$ and cardiorespiratory distress. ${ }^{5}$ In such patients, pericardial effusions can be massive, and absence of pericardial effusions may mean that the pericardium is not affected by the tumor. ${ }^{6}$ The clinical features, management and prognoses of fetal intrapericardial teratomas have not been sufficiently elucidated so far. The purpose of this article is to give an overview of the clinical features, management and prognoses of fetal intrapericardial teratomas.

\section{Material and Methods}

PubMed database and Yahoo! search engine were retrieved for publications reporting on fetal intrapericardial teratomas published in the past 20 years. The search terms included "(intra)pericardial teratoma" and "fetal/fetus/ fetuses". Bibliographic references were also tracked for the completeness of the literature retrieval.

Data were carefully extracted for details of the demographics of mother and fetus, and clinical features, management and prognoses of fetal intrapericardial teratomas.

Quantitative data were presented as mean \pm standard deviation with range and median 
values. The intergroup differences were compared by independent samples $t$-test, and comparisons of frequencies were made by Fisher's exact test. $p<0.05$ was considered statistically significant.

The research was reviewed and approved by an institutional review board on January 10, 2018 (approval number 20180106), and that no informed consent of participation involved was applicable for this review article.

\section{Results}

A total of 26 articles including 33 fetuses were collected, $7-32$ and one of the fetuses was a twin. ${ }^{15}$ Mothers aged 29.0 06.0 (range, 17-39; median, 29.5) years $(n=24)$, with a gravida of $1.9 \pm 0.8$ (range, $1-3$; median, 2) $(n=19)$, and a para of $0.7 \pm 0.8$ (range, $0-2$; median, 1) $(n=17)$. The gestational age at mother's presentation was $26.1 \pm 5.0$ (range, 18.9-38; median, 26) weeks $(n=30)$.

The timing of presence or detection of fetal pericardial/pleural effusions or ascites was 26.6 \pm 4.4 (range, 19-36; median, 27) weeks $(n=27)$, the timing of increase of the effusions was 28.3 \pm 5.1 (range, 23-34; median, 28) weeks $(n=5)$. Hydrops fetalis was present in $18(54.5 \%)$ cases. The timing of presence or detection of hydrops fetalis was $27.4 \pm 4.4$ (range, 19-34; median, 29) weeks $(n=18)$. No difference was found between timing of pericardial/pleural effusions or ascites and timing of hydrops fetalis $(\mathrm{p}=0.6002)$.

The diagnostic tools for the fetal intrapericardial teratomas were described in 26 (78.8\%) cases: by ultrasound in $19(73.1 \%)$, by fetal echocardiography in 13 (50\%), by magnetic resonance imaging in $6(23.1 \%)$ and by computed tomography in $2(7.7 \%)$ cases.

The tumors were initially detected at $34.1 \pm 14.0$ (range, 21-35; median, 30.8) weeks of gestation $(n=23)$. Tumor growth was observed in 19 $(57.6 \%)$ cases. The initial size of the fetal tumors was 26.2 \pm 4.6 (range, 18.9-36; median, 26) $\mathrm{mm}(\mathrm{n}=32)$, and the neonatal tumor size was 49.6 \pm 22.7 (range, 24.1-130; median, 45) $\mathrm{mm}(\mathrm{n}=19)$. A significant tumor growth was seen from the fetal to the neonatal period $(p<0.0001)$.

The arising sites of the tumors were described in $21(63.6 \%)$ cases: they were arising from the ascending aorta in $10(47.6 \%)$ cases, from the surface of the right atrium in $5(23.8 \%)$ cases, from the aorta and pulmonary artery/ great vessels in $3(14.3 \%)$ cases, from the pericardium in $1(4.8 \%)$ case, from right atrium, the right ventricle and the ascending aorta in $1(4.8 \%)$ case, and they surrounded the innominate vein, arch vessels and transverse aortic arch in $1(4.8 \%)$ case.

Tumor compression was observed in 14 (42.4\%) cases, and most of the structures compressed were right heart chambers (Table I). Only 1 (3.0\%) fetus was associated a cardiac structural defect -- patent ductus defect. Reaccumulation of the effusions developed in 9 (27.3\%) cases after the initial management for $1.9 \pm 1.2$ (range, 1-4; median, 1) time(s) $(\mathrm{n}=9)$.

The delivery time was $32.2 \pm 5.0$ (range, 19-40; median, 32) weeks of gestation $(n=25)$. The delivery modes were described in 26 cases: cesarean section in $19(73.1 \%)$ cases (one of the fetus was a twin), vaginal delivery in 3 $(11.5 \%)$ cases and termination of pregnancy in $4(15.4 \%)$ cases. Gender was described for $14(56 \%)$ neonates: $9(64.3 \%)$ were females and $5(35.7 \%)$ were males $\left(\chi^{2}=2.29, \mathrm{p}=0.131\right)$. Their birth weight was 2255.2 \pm 816.2 (range, 1100-4330; median, 2160) g $(n=19)$.

Twenty-five $(75.8 \%)$ fetuses received treatments for the teratomas. Prenatal centesis and postnatal tumor resection were required in most of the cases (Table II).

Pathology of the teratomas was reported for $28(84.8 \%)$ cases: 11 (39.3\%) were mature, 6

Table I. Tumor Compressions.

\begin{tabular}{lc}
\hline Adjacent structure compressed by tumor & $n(\%)$ \\
\hline RA, RV, superior vena cava & $4(28.6)$ \\
RA, superior vena cava & $2(14.3)$ \\
Aorta, systemic venous return & $1(7.1)$ \\
Heart & $1(7.1)$ \\
RA & $1(7.1)$ \\
RA, RV & $1(7.1)$ \\
Right heart chambers & $1(7.1)$ \\
Superior vena cava & $1(7.1)$ \\
Trachea, esophagus & $1(7.1)$ \\
Lung & $1(7.1)$ \\
\hline
\end{tabular}

RA: right atrium; RV: right ventricle. 
Table II. Management of Choices for Intrapericardial Teratomas of 25 Fetuses (55 Occasions).

\begin{tabular}{|c|c|c|c|}
\hline Manangement & $n(\%)$ & $\begin{array}{c}\text { Time } \\
\text { (gestational week or } \\
\text { days of life) }\end{array}$ & $\begin{array}{l}\text { Amount by } \\
\text { centesis or } \\
\text { drainage }(\mathrm{ml})\end{array}$ \\
\hline Antenatal & $27(49.1)$ & & \\
\hline Drug & $4(14.8)$ & & \\
\hline Steroids & $4(100)$ & & \\
\hline Maneuver & $23(85.2)$ & & \\
\hline Pericardiocentesis & $14(60.9)$ (18 times) & $30.0 \pm 3.5$ & $40.6 \pm 23.9$ \\
\hline Pericardiocentesis \& thoracocentesis & $2(8.7)$ & 29,30 & 8,22 \\
\hline Pericardial and pleural fluid drainage & $1(4.3)$ & 25.9 & 10,15 \\
\hline Amniotic fluid drainage & 1 (4.3) (3 times) & $31.1,32.1,32.9$ & $1350,1500,1600$ \\
\hline Pericardioamniotic shunt & $3(13.0)$ & $26.1 \pm 2.8$ & 30 \\
\hline Thoracoamniotic shunting & $2(8.7)$ & $29,30.7$ & \\
\hline Fetal & $3(5.5)$ & & \\
\hline Fetal surgery & $1(33.3)$ & 24 & \\
\hline EXIT & $2(66.7)$ & $24.1,31$ & \\
\hline Postnatal & $25(45.5)$ & & \\
\hline Drug & $3(12)$ & & \\
\hline Nonsteroid & $1(33.3)$ & & \\
\hline Anti-inflammatory treatment & $1(33.3)$ & & \\
\hline Intratracheal surfactant & $1(33.3)$ & & \\
\hline Maneuver & $2(8)$ & & \\
\hline Pleural effusion drainage & $1(50)$ & & \\
\hline Cardiac effusion drainage & $1(50)$ & & \\
\hline Tumor resection & $20(80)$ & $7.2 \pm 10.6$ & \\
\hline
\end{tabular}

EXIT: ex utero intrapartum treatment

(21.4\%) were immature, $3(10.7 \%)$ were mixed mature and immature with predominance of mature cells and $8(28.6 \%)$ were unspecified teratomas.

The neonates were at a follow-up of $11.5 \pm 9.4$ (range, 1-36; median, 10) months $(n=12)$. Fetoneonatal prognosis was described for $32(97.0 \%)$ cases: there were $11(34.4 \%)$ fetoneonatal deaths including 5 (45.5\%) fetal demises, 2 (18.2\%) neonatal deaths and 4 (36.4\%) terminations of pregnancies. In the remaining $21(65.6 \%)$ cases, $9(42.9 \%)$ had a neonatal comorbidity, $12(57.1 \%)$ were event-free survivals, and $2(9.5 \%)$ died of neonatal comorbidity. The survival rate was $59.4 \%$ (19/32). The neonatal comorbidities were respiratory distress in $3(33.3 \%)$, bronchopulmonary dysplasia in $2(22.2 \%)$ (one of them was associated with poor hemodynamics), bronchostenosis in 1 (11.1\%), pulmonary hypoplasia and extreme cardiomegaly in $1(11.1 \%)$, gastrointestinal perforation on day 11 requiring an ileostomy in 1 (11.1\%), and acute cardiac failure with respiratory insufficiency in 1 (11.1\%), respectively. The discharge date was described in $5(23.8 \%)$ neonates, and it was 56.2 \pm 77.7 (range, 2-181; median, 7) days $(\mathrm{n}=5)$.

$\alpha$-fetoprotein levels were reported in 5 fetuses with intrapericardial teratoma. The results generally showed a highest $\alpha$-fetoprotein level after birth and a gradually decreased $\alpha$-fetoprotein level with time (Table III).

\section{Discussion}

Kulthe et al. ${ }^{5}$ reported an infantile intrapericardial teratoma presenting with recurrent pericardial effusion and tamponade. Bader et al. ${ }^{8}$ stated that hydrops occurred in $77 \%$ of affected fetuses, and no correlation was found between tumor size and progressive hydrops. 


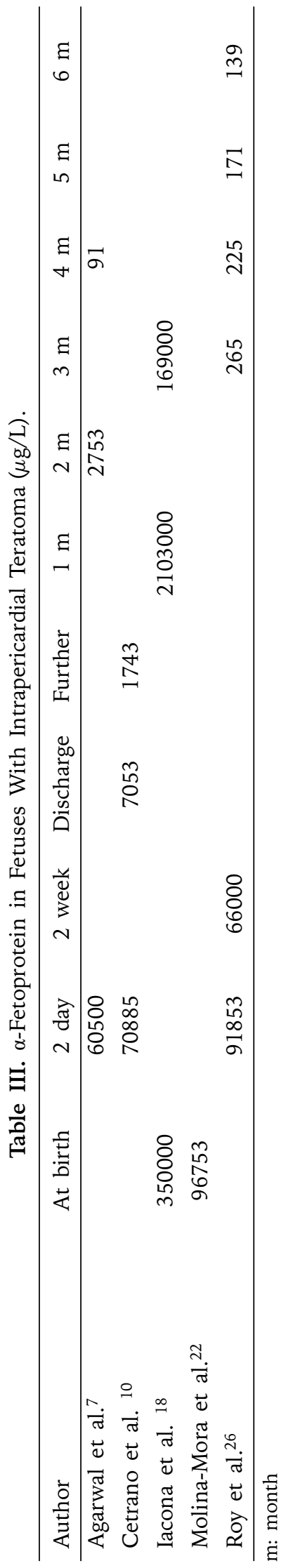

In infantile patients, signs of respiratory distress, cyanosis, superior vena cava obstruction, or cardiac tamponade should arouse the suspicion of an intrapericardial teratoma. ${ }^{5}$ Two-dimensional echocardiography is a golden standard diagnostic modality for intrapericardial teratomas, but magnetic resonance imaging may be helpful in outlining the relationships between the tumor and the adjacent structures. ${ }^{2}$ Nowadays, prenatal ultrasound and fetal echocardiography have greatly facilitated the early diagnosis of fetal intrapericardial teratomas. ${ }^{33}$ Doppler may help indicating the risks of hydrops fetalis. ${ }^{8}$

An elevated $\alpha$-fetoprotein level in maternal serum and amniotic fluid is a reliable indicator of a fetal abnormality, such as neural tube defects, omphalocele, gastroschisis and sacrococcygeal teratoma. ${ }^{34}$ The $\alpha$-fetoprotein was reported to be close to $100,000 \mu \mathrm{g} / \mathrm{L}$ at birth and decreases after an inverse logarithmic curve to approximately $100 \mu \mathrm{g} / \mathrm{L}$ at 1 month of life, and then to a normal level at 1 year of age. It has been suggested that the rapidity of $\alpha$-fetoprotein decay after resection of intrapericardial teratoma is a more accurate prognostic factor in immature teratomas than any isolated value. ${ }^{26}$

As for the prognoses of fetal intrapericardial teratomas, $42 \%$ died perinatally with 6 fetal and 4 neonatal deaths, and $58 \%$ survived. ${ }^{8}$ Nassr et al. ${ }^{33}$ summarized the data of 67 fetuses with intrapericardial teratoma, and 6 non-hydropic and 20 hydropic fetuses warranted fetal interventions, including 15 pericardiocenteses alone $(57.6 \%)$, pericardiocentesis followed by thoracocentesis and then placement of a thoraco-amniotic shunt $(n=1)$, pericardioamniotic shunt $(n=3)$, thoracentesis $(n=1)$, laser ablation $(n=2$, additional pericardiocentesis performed in one of these cases), ex utero intrapartum treatment (EXIT) to resection $(n=1)$, and open fetal surgery $(n=3)$. The survival rate of non-hydropic fetuses was much better than that of hydropic fetuses $(95.2 \%$ $(20 / 21)$ vs. $58.3 \%(28 / 46))$.

Perinatal maneuvers aim at improving fetal hemodynamic status and prolonging the pregnancy. ${ }^{33}$ Bader et al. ${ }^{8}$ summarized 11 of 31 fetal cases receiving fetal pericardial drainage at 22-33 week gestation: 4 (36.4\%) cases required multiple pericardiocenteses 
due to reaccumulation of fluid, 6 (54.5\%) cases received only once pericardiocentesis. ${ }^{8}$ Moreover, prenatal pericardio-amniotic shunt ensures continuous drainage of the pericardial effusions, avoids repeated pericardiocentesis and allows lung expansion. ${ }^{8}$

Open fetal surgery should be reassessed concerning the risk of a large hysterotomy during the operation. ${ }^{33}$ EXIT to tumor resection was once reported to obtain a promising outcome, but the impact of the procedure on later delivery and elective operation remains uncertain. ${ }^{33}$ Postnatal operation is almost curative and provides prompt relief of symptoms. ${ }^{5}$ It was reported that about $90 \%$ of intrapericardial teratomas were attached to the aorta or main pulmonary artery. ${ }^{35}$ Therefore, complete surgical excision can be performed with ease without the aid of cardiopulmonary bypass. ${ }^{35}$ But in the present review, we noted two cases were operated on on-pump due to tumor-related aortic obstruction, profound hypotension and aortic wall defect repair ${ }^{12}$ or due to bradycardia and hypotension. ${ }^{31}$ No recurrence has been reported after complete tumor resection. ${ }^{35}$

Fetal intrapericardial teratomas are rare and benign. However, they can be life-threatening owing to the associated massive pericardial effusions, tamponade, or cardiorespiratory distress. Symptomatic fetuses usually required perinatal maneuvers, such as pericardiocentesis, or thoraco-/pericardio-amniotic shunt in order to improve fetal hemodynamics and prolong the pregnancy for lung maturity. Open fetal surgery and EXIT can be considered but the impact of EXIT procedure on later delivery remains uncertain. Postnatal operation is a curative and symptom-relieving method for those cases with prenatally diagnosed intrapericardial teratomas. It has been proved that fetoneonatal outcomes are promising.

\section{REFERENCES}

1. Banfield F, Dick M 2nd, Behrendt DM, Rosenthal A, Pescheria A, Scott W. Intrapericardial teratoma: a new and treatable cause of hydrops fetalis. Am J Dis Child 1980; 134: 1174-1175.

2. Beghetti M, Prieditis M, Rebeyka IM, Mawson J. Images in cardiovascular medicine. Intrapericardial teratoma. Circulation 1998; 97: 1523-1524.

3. Yuan SM. Cardiac etiologies of hydrops fetalis. Z Geburtshilfe Neonatol 2017; 221: 67-72.
4. Yuan SM. Fetal primary cardiac tumors during perinatal period. Pediatr Neonatol 2017; 58: 205-210.

5. Kulthe SG, Nadkarni UB, Singh A, Deshmukh CT, Jain MK, Shah MD. Recurrent cardiac tamponade: intrapericardial teratoma. Indian Pediatr 1995; 32: 88-91.

6. Aldousany AW, Joyner JC, Price RA, Boulden T, Watson D, Disessa TG. Diagnosis and treatment of intrapericardial teratoma. Pediatr Cardiol 1987; 8: 51-53.

7. Agarwal A, Rosenkranz E, Yasin S, Swaminathan S. EXIT procedure for fetal mediastinal teratoma with large pericardial effusion: a case report with review of literature. J Matern Fetal Neonatal Med 2018; 31: 1099-1103.

8. Bader R, Hornberger LK, Nijmeh LJ, et al. Fetal pericardial teratoma: presentation of two cases and review of literature. Am J Perinatol 2006; 23: 53-58.

9. Cavalcante CTMB, Pinto Júnior VC, Pompeu RG, et al. Early treatment of intrapericardial teratoma: A case presentation and systematic literature review. J Matern Fetal Neonatal Med 2019; 32: 2262-2268.

10. Cetrano E, Polito A, Carotti A. Primitive intrapericardial teratoma associated with yolk sac tumour. Cardiol Young 2015; 25: 158-160.

11. Czernik C, Stiller B, Hübler M, Hagen A, Henrich W. Hydrops fetalis caused by a large intrapericardial teratoma. Ultrasound Obstet Gynecol 2006; 28: 973-976.

12. Daniels CJ, Cohen DM, Phillips JR, Rowland DG Prenatal detection of a pericardial teratoma. Circulation 1999; 99: E1-E2.

13. de Bustamante TD, Azpeitia J, Miralles M, Jiménez M, Santos-Briz A, Rodríguez-Peralto JL. Prenatal sonographic detection of pericardial teratoma. J Clin Ultrasound 2000; 28: 194-198.

14. Devlieger R, Hindryckx A, Van Mieghem T, et al. Therapy for foetal pericardial tumours: survival following in utero shunting, and literature review. Fetal Diagn Ther 2009; 25: 407-412.

15. Fagiana AM, Barnett S, Reddy VS, Milhoan KA. Management of a fetal intrapericardial teratoma: a case report and review of the literature. Congenit Heart Dis 2010; 5: 51-55.

16. Goldberg SP, Boston US, Turpin DA, et al. Surgical management of intrapericardial teratoma in the fetus. J Pediatr 2010; 156: 848-849, 849.e1.

17. Grebille AG, Mitanchez D, Benachi A, et al. Pericardial teratoma complicated by hydrops: successful fetal therapy by thoracoamniotic shunting. Prenat Diagn 2003; 23: 735-739.

18. Iacona GM, Barber MA, Medina M, Abella R. Intrapericardial teratoma in a low birth weight preterm infant: a successful multidisciplinary approach. Interact Cardiovasc Thorac Surg 2011; 12: 287-289.

19. Kamil D, Geipel A, Schmitz C, et al. Fetal pericardial teratoma causing cardiac insufficiency: Prenatal diagnosis and therapy. Ultrasound Obstet Gynecol 2006; 28: 972-973.

20. Kitagawa N, Ohhama Y, Fukuzato Y, et al. Pericardial hemangioma presenting fetal cardiac tamponade and postnatal bronchostenosis. Pediatr Surg Int 2004; 20: 376-377. 
21. Mitanchez D, Grébille AG, Parat S, et al. Delayed surgery in pericardial teratoma with neonatal hydrops. Eur J Pediatr Surg 2005; 15: 431-433.

22. Molina-Mora MJ, Picazo-Antolín B, Cuenca-Peiró V, Miguel Gil-Jaurena J, Zabala-Argüelles JI. Foetal intrapericardial teratoma. Eur J Echocardiogr 2011; 12: 513.

23. Pachy F, Raiffort C, Mechler C, Zilberman S, Mandelbrot L. Intrapericardial teratoma with hydrops leading to in utero demise. Prenat Diagn 2007; 27: 970-972.

24. Ragupathy R, Nemeth L, Kumaran V, Rajamani G, Krishnamoothy P. Successful surgical management of a prenatally diagnosed intrapericardial teratoma. Pediatr Surg Int 2003; 19: 737-739.

25. Ramírez JA, Mon CR, Perez EO, Parugues BD, Pascual GR. Fetal intrapericardial teratoma. Ultrasound Obstet Gynecol 2004; 23: 416-418.

26. Roy N, Blurton DJ, Azakie A, Karl TR. Immature intrapericardial teratoma in a newborn with elevated alpha-fetoprotein. Ann Thorac Surg 2004; 78: e6-e8.

27. Rychik J, Khalek N, Gaynor JW, et al. Fetal intrapericardial teratoma: natural history and management including successful in utero surgery. Am J Obstet Gynecol 2016; 215: 780.e1-780.e7.

28. Skálová H, Povýsil C. Intrapericardial teratoma as a cause of fetal death--a case report. Cesk Patol 2011; 47: 189-191.
29. Steffensen TS, Quintero RA, Kontopoulos EV, GilbertBarness E. Massive pericardial effusion treated with in utero pericardioamniotic shunt in a fetus with intrapericardial teratoma. Fetal Pediatr Pathol 2009; 28: 216-231.

30. Sydorak RM, Kelly T, Feldstein VA, et al. Prenatal resection of a fetal pericardial teratoma. Fetal Diagn Ther 2002; 17: 281-285.

31. Tollens M, Grab D, Lang D, Hess J, Oberhoffer R. Pericardial teratoma: prenatal diagnosis and course. Fetal Diagn Ther 2003; 18: 432-436.

32. Tomek V, Vlk R, Tláskal T, Skovránek J. Successful pericardio-amniotic shunting for fetal intrapericardial teratoma. Pediatr Cardiol 2010; 31: 1236-1238.

33. Nassr AA, Shazly SA, Morris SA, et al. Prenatal management of fetal intrapericardial teratoma: A systematic review. Prenat Diagn 2017; 37: 849-863.

34. Lee H, Hirose S, Harrison MR. Chapter 5 - Prenatal diagnosis and fetal therapy. Pediatric Surgery $\left(7^{\text {th }}\right.$ ed). 2012: 77-88. https://doi.org/10.1016/B978-0-32307255-7.00005-2

35. Paw PT, Jamieson SW. Surgical management of intrapericardial teratoma diagnosed in utero. Ann Thorac Surg 1997; 64: 552-554. 